3 Archibald RM, German J. The Aarskog-Scott syndrome in four brothers. Birth Defects 1975;2(2):25-9.

4 Bartsocas CS, Dimitrou JK. Aarskog-Scott syndrome of unusual facies, joint hypermobility, genital anomaly and short stature. Birth Defects 1975;2(2):453-5.

5 Kirkham TH, Milot J, Berman P. Ophthalmic manifestations of Aarskog (facial-digital-genital) syndrome. Am J Ophthalmol 1975;79:441-5.

6 Schulze C. Developmental abnormalities of the teeth and jaws. In: Gorlin RJ, Goldman HM, eds. Thoma's oral pathology. St Louis: Mosby, 1970:96-183.

7 Passarge E. The genetics of Hirschsprung's disease. $N$ Engl J Med 1967;276:138-43.

${ }^{8}$ Gordon H, Torrington M, Louw JH, Cywes S. A genetical study of Hirschsprung's disease. $S$ Afr Med $J$ 1966;40: 720-1.

9 Bolande RP. The neurocristopathies. Hum Pathol 1974; 5:409-29.

10 McCredie J, Cameron J, Shoobridge R. Congenital malformations and the neural crest. Lancet $1978 ; 2: 761-3$.

11 Fisch L. Deafness as part of an hereditary syndrome. $J$ Laryngol Otol 1959;73:355-82.

12 Bergsma D, ed. In: Birth defects. Atlas and compendium. Baltimore: Williams and Wilkins, 1973:325, 427.

Requests for reprints to Dr John J Mulvihill, Clinical Epidemiology Branch, National Cancer Institute, Landow Building, Room 5A21, Bethesda, Maryland 20205, USA.

\section{A digitopalatal syndrome with associated anomalies of the heart, face, and skeleton}

SUMMARY A syndrome of multiple anomalies associated with growth failure and delayed development is described. The facies appear distinctive with globular head, prominence of the eyes, hypertelorism, cleft palate, micrognathia, and abnormal pinnae. Other features include vertebral and costal anomalies, cardiac defects, and a peculiar malformation of the hands. At least five other cases of this condition, all occurring in males, may be found in medical reports. The finding of incomplete expression in three maternal relatives of our patient provides evidence for a genetic cause.

A syndrome of uncertain aetiology but unified by anomalies of the craniofacial structures, hands, heart, and vertebrae has been reported in five cases during the past 12 years. ${ }^{1-4}$ Although usually reported as the Pierre Robin syndrome, these patients have distinc- tive features in addition to the mandibulomaxillary dysplasia. Of particular note is the peculiar hand formation with an accessory bone proximal to the first phalanx of the index fingers. This complex of anomalies results from disturbance during the first eight weeks of embryonic development. In contrast to the defects seen in the Pierre Robin syndrome, the components of this syndrome cannot be easily envisaged as anomalous derivatives of a single primary defect.

We describe here the sixth case, a male, having all of the features previously reported. Features of the syndrome were found in three maternal relatives, providing evidence for a genetic cause.

\section{Case report}

The proband (IV.4) was born after a term gestation $\stackrel{\infty}{\infty}_{\infty}$ to a 19-year-old unmarried mother and a 22-year-old 응 father. The mother, a sufferer of chronic emotional problems, took amitriptyline (Elavil) and trifluoperazine (Stelazine) regularly during the first $2 \frac{1}{2}$ months of pregnancy. At $3 \frac{1}{2}$ months she took an overdose of amitriptyline $(1050 \mathrm{mg})$ requiring admission to hospital. Her initial findings were

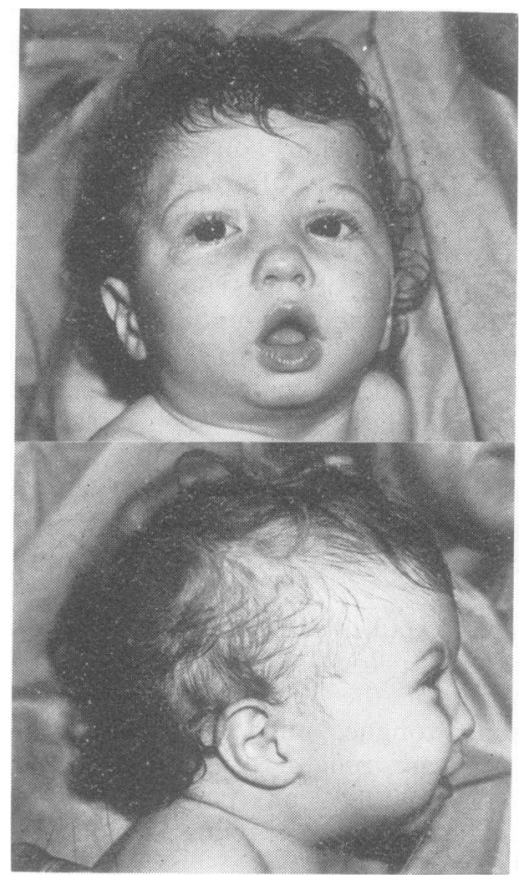

FIG 1 Frontal and lateral facial appearance of proband at age 15 months. Note the globular head, micrognathia, and low-set retroverted pinnae. 


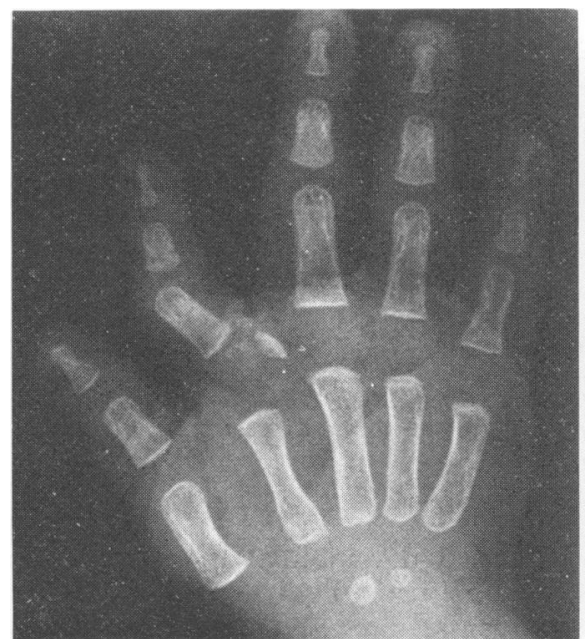

(a)

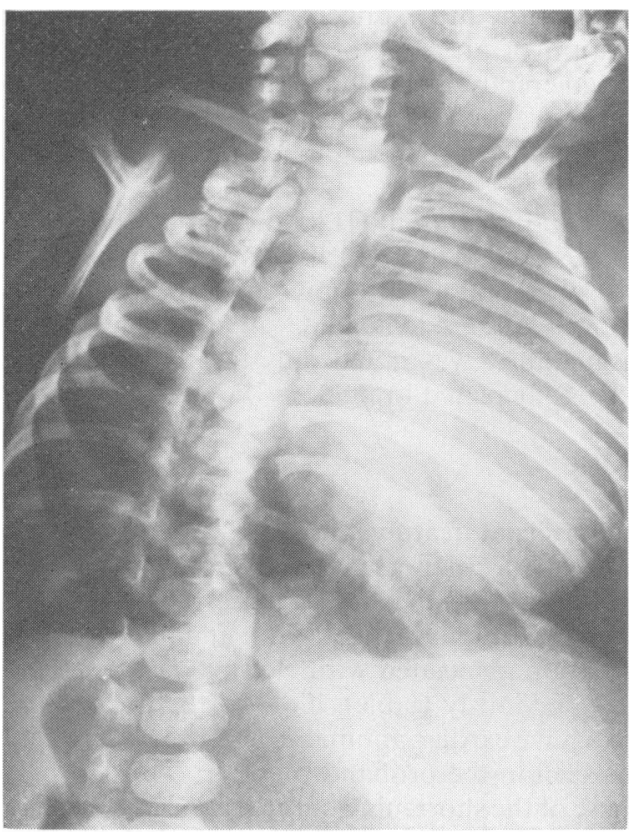

(c)

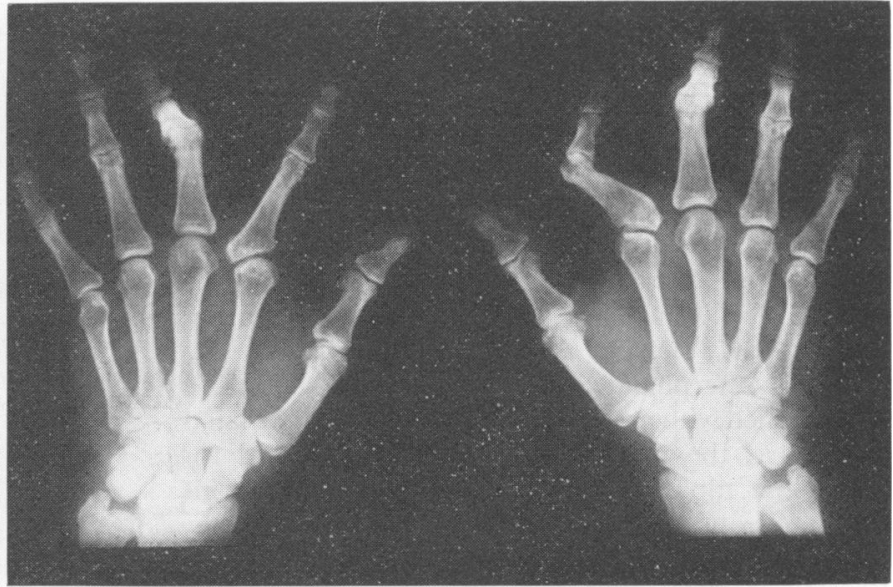

(b)

FIG 2 (a) X-ray of right hand of proband showing accessory bones at the base of the second digit and hypoplasia of the second metacarpal and phalanges. (b) X-ray of hands of II.6 showing angulation of digits and malformation of the proximal portion of first phalanx of the index fingers. (c) X-ray of chest of proband showing multiple vertebral anomalies in the cervical and dorsal spine.

uncontrollable behaviour and hallucinations, followed by a period of unresponsiveness. She was treated initially with physostigmine salicylate (Antillirium) and recovered uneventfully. At $2 \frac{1}{2}$ months' gestation, she underwent tonsillectomy and adenoidectomy, during which time she received diazepam (Valium), succinylcholine (Anectine), fentanyl (Suplimaze), and sodium thiopental (Centothal). She also received metronidazole (Flagyl) for a trichomonas infection during the first couple of months of pregnancy. She smoked one packet of cigarettes a day during the first half of pregnancy and half a pack a day thereafter. Alcohol consumption was reported to be less than 'four cans of beer' weekly. The father smoked marijuana and sniffed paint before the pregnancy and reportedly used other street drugs as well.

At birth, the proband weighed $3.4 \mathrm{~kg}$ (50th centile), 
had a head size of $34 \mathrm{~cm}$ ( 25 th centile), and length of $47 \mathrm{~cm}$ (10th centile). The craniofacial features included globular head configuration with an anterior fontanelle of $3 \mathrm{~cm}$ and a posterior fontanelle of $0.5 \mathrm{~cm}$, prominent eyes, low-set ears with deficient superior ear cartilages, prominent anthelix and absent lobe, marked micrognathia, cleft palate, and short neck with mild webbing (fig 1). The chest was asymmetrical with the major cardiac impulse felt at the midline. A loud systolic murmur could be heard over the entire chest. A mild pectus excavatum was present. Fingers 2 to 4 were flexed at the proximal interphalangeal (PIP) joint but could be straightened with pressure. The second finger deviated radially at the metacarpophalangeal joint and towards the ulna at the PIP joint. The fingerprint configurations on the right were UL, R, UL, UL, UL, and on the left were UL, underdeveloped, UL, W, UL.

$X$-ray examination showed multiple vertebral anomalies extending from $\mathrm{C} 2$ to $\mathrm{D} 7,13$ ribs on the right side and 11 ribs on the left side, and an accessory bone at the base of the second digit of the hands bilaterally (fig $2 \mathrm{a}$ ). The second metacarpals were short as were the distal two phalanges of the index fingers.

The nursery period passed uneventfully with only mild respiratory distress noted in the initial hours of life. A left sided pneumonia occurred at 2 weeks of age. Cardiac catheterisation at one month of age showed a large VSD with pulmonary hypertension and dextrorotation with most of the heart on the right side of the chest. Chromosome analysis with $\mathrm{Q}$ banding appeared normal.

Growth progressed at a slow rate with all measurements falling well below the 3rd centile at the age of 15 months (head circumference $44 \mathrm{~cm}$, length $67 \mathrm{~cm}$, and weight $7.3 \mathrm{~kg}$ ). The facies were striking with globular head, flat profile, small nose, hypertelorism, prominent eyes, cleft palate, and micrognathia (fig 1). The chest remained asymmetrical and a loud systolic murmur could be heard over the entire precordium. The hand deformity was as previously described except that the flexed position was limited to the second finger. Language and gross motor skills were at the 9-month level with fine motor and personal skills at the 12-month level.

The mother (III.7) is now 22-years-old and in good health except for nervousness. Her hands, spine, and heart are normal by clinical and radiological examination.

The maternal grandfather (II.6) is 57 years old and in good health. He has malformations of both hands, the right index finger having the identical configuration to the index fingers of the proband, the left index

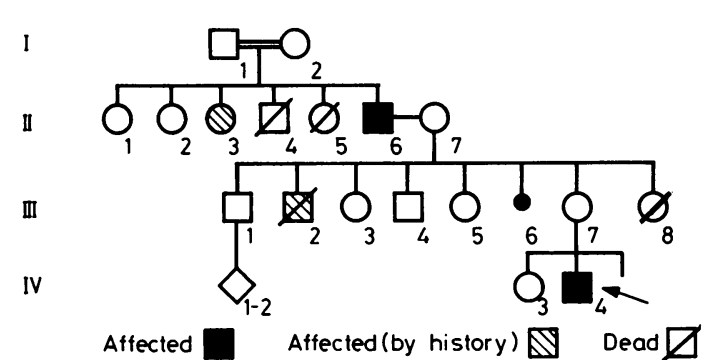

FIG 3 Partial pedigree of family of proband (IV.4). Note consanguinity in generation I and possible male to male transmission.

finger having radial deviation at the metacarpophalangeal joint only, and digits 3 to 5 bilaterally having flexion contractures at the proximal interphalangeal joints. $X$-rays show abnormal proximal phalanges of the index fingers, presumably resulting from fusion of an accessory bone to the proximal phalangeal epiphysis (fig 2b). The palate is intact, the heart normal, and the spine straight. $X$-rays show multiple vertebral abnormalities extending from $\mathrm{C} 8$ to T5.

A maternal great aunt (II.3) and a maternal uncle (III.2) are said to have had the same hand anomaly as the proband. Both are now dead and no photographs or $x$-rays are available.

Consanguinity was noted only in generation I of the pedigree depicted in fig 3.

\section{Discussion}

The craniofacial features, cardiac anomalies, and peculiar hand malformation described in the proband constitute a repeatable pattern of malformations. Five additional patients with an identical hand malformation associated with cleft palate have been reported previously (table). Two of these cases are known to have cardiac anomalies and the craniofacial features seen in the proband. ${ }^{24}$

Because of the shortening of the second metacarpal, the accessory bone at the base of the second digit has been interpreted as an accessory metacarpal by Manzke $^{1}$ who suggests that the extra bone arises as a metacarpal and is pushed distally in the soft tissue to its final location at the base of the second phalanx. The origin of the extra bone remains unclear to us. The location of the accessory bone, as well as the observation in our case and in the cases reported by Manzke $^{1}$ and by Holthusen ${ }^{3}$ that it eventually fuses with the proximal phalangeal epiphysis, suggests that it is an accessory phalanx rather than a metacarpal. Although previously described in relation to

.


TABLE Features in 7 reported cases of digitopalatal syndrome

\begin{tabular}{|c|c|c|c|c|c|c|c|}
\hline & \multicolumn{2}{|c|}{ Present cases } & \multirow[t]{2}{*}{ Gewitz et al 4} & \multirow{2}{*}{$\begin{array}{l}\text { Farnsworth } \\
\text { and Pacik }\end{array}$} & \multicolumn{2}{|c|}{ Holthusen ${ }^{3}$} & \multirow[t]{2}{*}{ Manzke ${ }^{1}$} \\
\hline & Case IV.4 & Case II.6 & & & Case 5 & Case 6 & \\
\hline Birthweight (g) & 3400 & - & 3210 & 2550 & - & - & - \\
\hline \multicolumn{8}{|l|}{ Craniofacial } \\
\hline Globular head & + & $\mathbf{0}$ & $t^{*}$ & $+*$ & - & - & 一 \\
\hline Prominent eyes & + & $\mathbf{0}$ & $t^{*}$ & $+^{*}$ & - & 一 & - \\
\hline Cleft palate & + & 0 & + & + & + & + & + \\
\hline Micrognathia & + & 0 & + & + & + & - & + \\
\hline Cardiac defect & $+($ VSD $)$ & $\mathbf{0}$ & $+(\mathrm{ASD})$ & $+(\mathrm{VSD})$ & - & - & - \\
\hline \multicolumn{8}{|l|}{ Skeletal defect } \\
\hline Hand anomaly & + & + & + & + & $+(1)$ & + & + \\
\hline Deficient nails of toes & + & 0 & 0 & 0 & - & - & - \\
\hline Club foot & 0 & 0 & $\mathbf{0}$ & + & 一 & + & 0 \\
\hline Vertebral anomalies & + & + & - & 0 & 一 & - & - \\
\hline Chest deformity & + & 0 & 一 & - & - & 一 & + \\
\hline Sex & $\mathbf{M}$ & $\mathbf{M}$ & $\mathbf{M}$ & $\mathbf{M}$ & $\mathbf{M}$ & $\mathbf{M}$ & $\mathbf{M}$ \\
\hline Family history & + & + & + & $\mathbf{0}$ & $\mathbf{0}$ & 一 & 0 \\
\hline Parental drug abuse & + & - & 0 & + & $\mathbf{0}$ & 一 & 一 \\
\hline
\end{tabular}

+ present

+ *discerned from photographs in original publication

0 feature not present

- no comment in report or unknown

(1) this patient also had bifurcation of 1 st metatarsal of right foot

Pierre Robin anomalies, this syndrome would appear separable on the basis of the features enumerated. Additionally, the hypoplastic development of the mandible appears more dramatic with age, whereas in the Pierre Robin syndrome the faciomandibular disharmony tends to lessen with age. These patients have some features in common with those described as the VACTERL anomalies, but lack renal, tracheo-oesophageal, and anal anomalies. Furthermore, the peculiar hand formation noted in these patients with an accessory phalanx present at the proximal aspect of the second digit of the hand bilaterally appears unique. In several of these patients growth failure and slow development has been noted during childhood. The growth retardation probably results from poor nutrition and repeated illnesses since the birthweights were within the normal range.

In our case and in the case of Farnsworth and Pacik, ${ }^{2}$ the fathers reportedly used street drugs, and in our case the mother repeatedly used several drugs including amitriptyline and trifluoperazine in early pregnancy. Although amitriptyline has been associated with limb defects in the past, no causal relationship has been established. ${ }^{56}$ It is of interest to note that Wertelecki and associates have reported an infant with micrognathia, cleft palate, and other anomalies born to a mother who ingested an overdose of amitriptyline during the first month of pregnancy. ${ }^{7}$

The present family provides evidence for a genetic cause, although the mode of transmission cannot be stated without reservation. Possible male to male transmission would indicate autosomal dominant transmission. This is held with some reservation, however, since the two subjects (II.3 and III.2) who would be most informative are dead and medical records contain no comment regarding abnormal features.

A previous pregnancy in the mother of the child reported by Gewitz et $a l^{4}$ had resulted in a stillborn male infant with 'classical Pierre Robin syndrome' and an atrial septal defect. Unfortunately no description of the hands was included in the necropsy report on this infant.

Further cases will need to be evaluated to confirm the mode of inheritance, to delineate the range and frequency of expression of the various features of the syndrome, and to determine whether the syndrome is sex limited.

Roger E SteVenson, Harold a Taylor Jr, O Marion Burton, aNd HeNRy B Hearn III Greenwood Genetic Center, Greenwood, South Carolina, and the Family Practice Center, Anderson, South Carolina, USA

\section{References}

1 Manzke VH. Symmetrische hyperphalangie des zweiten fingers durch ein akzesorisches metacarpale. ROEFO 1966;105:425-7.

2 Farnsworth PB, Pacik PT. Glossoptotic hypoxia and micrognathia-the Pierre Robin syndrome reviewed. Clin Pediatr 1971;10:600-6. 
3 Holthusen W. The Pierre Robin syndrome: unusual associated developmental defects. Ann Radiol (Paris) $1972 ; 15: 253-62$.

4 Gewitz M, Dinwiddie R, Yuille T, Hill E, Carter CO. Cleft palate and accessory metacarpal of index finger syndrome: possible familial occurrence. $\mathrm{J} \mathrm{Med}$ Genet 1978;15:162-4.

5 Banister P, Dafoe C, Smith ESO, Miller J. Possible teratogenicity of tricyclic anti-depressants. Lancet 1972; $1: 838$.
- Freeman R. Limb deformities: possible association with $\frac{\mathbb{D}}{\overparen{D}}$ drugs. Med J Aust 1972;1:606-7.

7 Wertelecki W, Purvis-Smith SG, Blackburn WR. Amitriptyline/perphenazine maternal overdose and birth $\stackrel{\vec{D}}{ }$ defects. Am J Hum Genet 1978;30:105A.

Requests for reprints to Dr R E Stevenson, Green- $\frac{\bar{c}}{\omega}$ wood Genetic Center, 1020 Spring Street, Greenwood, South Carolina 29646, USA.

\section{Correction}

In the December 1979 issue of the Journal, in the Case report by Gerli et al on page 481, the second X chromosome in fig 2 was inadvertently printed upside down. 